\section{Reafirmar o direito à saúde, defender o SUS e construir justiça social: Tese do Cebes 2021- 2022}

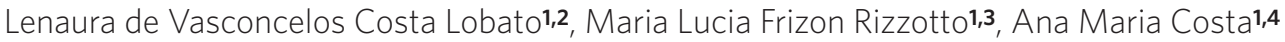

SEGUINDO SUA MISSÃO DE AMPLIAR O CONHECIMENTO e o pensamento crítico em saúde e dar voz às inúmeras demandas sociais e de saúde dos brasileiros, o Centro Brasileiro de Estudos de Saúde (Cebes) realizou, nos dias 9 e 10 de dezembro de 2021, seu VIII Simpósio', orientado pelo tema Reforma Sanitária em Tempos de Fascismo e Neoliberalismo. Como é prática desde 2009, quando foi realizado o I Simpósio Cebes de Políticas de Saúde, no processo de refundação do Cebes, os simpósios bianuais visam analisar e discutir a conjuntura setorial, social e política, definindo as diretrizes e orientações para a ação das diretorias, núcleos e demais instancias da entidade.

O VIII Simpósio foi uma oportunidade de debate entre associados do Cebes com especialistas e lideranças do movimento social. Em um primeiro momento, o debate contou com a presença de João Pedro Stédile, do Movimento Sem Terra (MST), e da professora Sonia Fleury, que trataram da conjuntura nacional e internacional caracterizando as evidências explicitadas pela crise sanitária da pandemia da Covid-19 e a profunda crise do capitalismo, acarretando consequências dramáticas para a saúde. Destacou-se a tragédia do governo Bolsonaro na condução do País e no enfrentamento da pandemia como parte de um projeto de radicalização do liberalismo com franca aliança com o mercado e redirecionamento do papel do Estado, que se retira das atribuições de proteção da população. Esse desmonte do projeto de país praticado no Brasil sufoca e constrange a democracia por diversos mecanismos, especialmente reconhecível no seu viés autoritário e apoio nas forças armadas. A conjuntura e os desafios setoriais foram debatidos por dois convidados e integrantes do Cebes, Jairnilson Silva Paim e Ligia Bahia, que analisaram o setor da saúde nacional, os desafios do Sistema Único de Saúde (SUS) e as características e relações que vêm orientando o setor privado. Essa reflexão aponta o desmonte de políticas de saúde bem-sucedidas e a valorização intensa e crescente do setor privado, confirmando o processo de financeirização do setor, especialmente a assistência, com graves consequências para o direito e acesso universal à saúde. Reafirmando a tese do Cebes sobre a importância da organização e mobilização política para o enfrentamento do desmonte do direito à saúde, esse debate identifica e valoriza o vigor dos movimentos sociais na defesa da democracia e da saúde que tem crescido e diversificado, apesar de restrições de toda ordem ${ }^{1}$ que vêm sendo impostas.

Celebrando a participação de mais de 300 pessoas, o Cebes avalia que o VIII Simpósio confirma a relevância, a necessidade e a atualidade da luta pela reforma sanitária, reafirmando a exigência de que ela seja o norte das proposições e da luta do campo democrático para a saúde.

\footnotetext{
${ }^{1}$ Centro Brasileiro de Estudos de Saúde (Cebes) - Rio de Janeiro (RJ), Brasil. lenauralobato@uol.com.br

2 Universidade Federal Fluminense (UFF) - Niterói (RJ), Brasil.

3 Universidade Estadual do Oeste do Paraná (Unioeste) - Cascavel (PR), Brasil.

${ }^{4}$ Escola Superior de Ciências da Saúde (Escs) Brasília (DF), Brasil.
} 
Nesse sentido, muito se debateu sobre o ano eleitoral e a premência da pauta do direito à saúde entre nas plataformas dos candidatos, tanto à presidência quanto aos governos estaduais, deputados e senadores. Esta será a tarefa central dos cebianos em 2022: discutir com candidatos progressistas a defesa do direito à saúde no seu sentido ampliado e a ampliação do SUS público.

Para isso que o Cebes construiu e publicou sua Tese 2021-2022², discutida e consensuada entre cebianos ao longo do ano e aprovada na sua Assembleia geral em 10 de dezembro de 2021. As teses do Cebes consolidam e expressam os debates sobre a conjuntura internacional e nacional e evidenciam o contexto como a saúde e o SUS são afetados. Para sua elaboração, contou com a contribuição de diversos encontros denominados 'Cebes Debate', realizados ao longo do ano, com a participação de lideranças e especialistas nos mais diversos temas atinentes à saúde e à democracia. Esse processo que foi coroado no VIII Simpósio atualiza e sistematiza conclusões que consolidam os princípios e as estratégias para a ação do conjunto da entidade nos próximos anos.

Sob o lema que fundou o Cebes, SAÚDE É DEMOCRACIA, DEMOCRACIA É SAÚDE, a tese discute o padrão global vigente de universalização do mal-estar, com o agravamento das desigualdades e com o aumento exponencial da fome e da miséria, demonstrando a incapacidade do capitalismo, cada vez mais financeirizado e concentrado, de prover segurança e bem-estar às populações. Destaca a necessidade de ampliação da participação e organização popular para a construção de alternativas democráticas voltadas, de fato, às maiorias. No caso brasileiro, a tese destaca o padrão excludente de nossa história, que retorna, hoje, com força, no projeto neoliberal e autoritário de nossas elites, sem compromisso com os interesses nacionais. O SUS não escapa a esse modelo concentrador, lidando cotidianamente com as tentativas de restringi-lo, fragilizá-lo, para favorecer interesses privados, à custa dos recursos e da saúde dos brasileiros.

A Tese ${ }^{2}$ enfatiza os princípios e diretrizes da luta do Cebes.

\section{Princípios irrevogáveis do Cebes}

- Defender o direito universal à saúde e a justiça social.

- Defender intransigentemente a democracia com ampliação da consciência crítica por direitos, combatendo e revertendo as tendências destrutivas do capitalismo.

- Manifestar-se firmemente contra todas as guerras, contra a indústria bélica e contra a liberdade de porte de arma.

- Lutar contra o fascismo e todas as formas de intolerância.

- Repudiar e denunciar todas as formas de violência, incluindo a pena de morte, a violência urbana, doméstica, de gênero, institucional e em saúde.

- Defender o pluralismo social, denunciando e repudiando o patriarcado, a homofobia, a lesbofobia, a transfobia e o racismo.

- Defender a descriminalização das drogas.

- Defender a legalização do aborto e os direitos sexuais e reprodutivos. 


\section{Bases e princípios da luta do Cebes por Democracia e Saúde no Brasil}

- Defender o sistema de saúde para todos os brasileiros 100\% público, integral, de qualidade, com prestadores estatais e sem incentivo ou subvenção à prática privada.

- Lutar contra a expansão do setor privado da saúde.

- Difundir e divulgar para a sociedade as limitações dos planos privados ante o sistema público.

- Defender a eliminação de novos contratos do SUS com o setor privado e revisar os atuais.

- Defender a extinção de subsídios, isenções fiscais e perdão de multas para o setor privado.

- Defender a extinção de processos de privatizações e terceirizações na saúde.

- Lutar por financiamento justo e adequado para a saúde e o SUS, com destaque para o papel da União.

- Defender que os fóruns de decisão de Conselhos, Diretorias, Diretorias Colegiadas e órgãos deliberativos de todas as Agências de Estado (Agência Nacional de Saúde Suplementar ANS, Agência Nacional de Vigilância Sanitária - Anvisa e de outras agências) sejam paritários, com $50 \%$ de votos e participação dos usuários de cada setor regulado.

- Apoiar o fortalecimento da participação popular para a construção da democracia popular na saúde.

- Democratizar os Conselhos estaduais, municipais e locais de saúde e torná-los deliberativos.

- Defender uma política nacional da força de trabalho em saúde.

- Defender Planos de Cargos e Salários para os profissionais de saúde.

- Defender o modelo de atenção que supere a perspectiva médico-privatista e que se baseie no cuidado humano e nos princípios da universalidade, igualdade, integralidade e autonomia.

- Apoiar os ajustes na formação acadêmica dos profissionais de saúde, aproximando-os das necessidades do SUS.

- Lutar pela devolução do poder de administrar, planejar e executar a atenção à saúde em rede ao Ministério da Saúde, com destaque para a atenção primária, com a extinção da Agência para o Desenvolvimento da Atenção Primária à Saúde (Adaps).

- Defender a democratização da Política Nacional de Informação e Informática em Saúde (PNIIS) e a participação social no Comitê Gestor da Estratégia de Saúde Digital. 
- Promover diálogos entre as entidades acadêmicas, sindicais, partidos e movimentos sociais, retomando a luta por seguridade social, políticas universalistas e de saúde.

- Lutar pela revogação das contrarreformas e retrocessos aos direitos sociais, em especial o teto de gastos (EC-95).

- Defender uma reforma fiscal que redistribua a carga tributária, como impostos, taxas e contribuições sociais, diminuindo os impostos sobre os mais pobres e sobre a classe média, como os impostos sobre consumo, e aumentando os impostos sobre os mais ricos.

- Contribuir para eleger representantes para o Executivo e o Legislativo do campo democrático popular, privilegiando os interesses da população e a plena democracia.

Com esses princípios e diretrizes, os cebianos irão à luta em 2022 para mudar o governo e instituir um novo projeto de País: soberano, democrático, justo e solidário para todos os brasileiros.

\section{Colaboradoras}

Lobato LVC (0000-0002-2646-9523)*, Rizzotto MLF (0000-0003-3152-1362)* e Costa AM (0000-0002-1931-3969)* contribuíram igualmente para a elaboração do manuscrito.

\section{Referências}

1. Centro Brasileiro de Estudos de Saúde. Em seu VIII Simpósio, Cebes reforça a defesa intransigente do direito à saúde. In: VIII Simpósio do Centro Brasileiro de Estudos da Saúde; 2021 dez 9-10; [on-line]. Rio de Janeiro: Centro Brasileiro de Estudos de Saúde. [acesso em 2022 jan 10]. Disponível em: https://cebes.org.br/em-seu-viii-simposio-cebes-reforca-a-defesa-intransigente-do-direito-a-saude/27752/.
2. Centro Brasileiro de Estudos de Saúde. Tese 20212022. Por um mundo multilateral: por nova hegemonia geopolítica global, civilização x barbárie. Rio de Janeiro: Centro Brasileiro de Estudos de Saúde; 2021. [acesso em 2022 jan 10]. Disponível em: https://cebes.org.br/tese-2021-22-cebes-reafirma-a-luta-civilizacao-contra-barbarie/28043/. 